\title{
Thermomechanical Behaviour of Poly(methyl methacrylate)/Copoly(ether-ester) Blends
}

\author{
P. Poomalai, ${ }^{1}$ T. O. Varghese, ${ }^{2}$ and Siddaramaiah ${ }^{3}$ \\ ${ }^{1}$ R\&D Department, Central Institute of Plastics Engineering and Technology, City Centre, P.O. Debhog, \\ Haldia, District Purba, Medinipur 721 657, India \\ ${ }^{2}$ Plastic Processing Department, Central Institute of Plastics Engineering and Technology, IDA, Phase-II, \\ Cherlapally, Hyderabad 500 051, India \\ ${ }^{3}$ Department of Polymer Science and Technology, Sri Jayachamarajendra College of Engineering, Karnataka, \\ Mysore 570 006, India
}

Correspondence should be addressed to P.Poomalai, poomalaip@rediffmail.com

Received 30 April 2011; Accepted 24 May 2011

Academic Editors: D. Chicot, M. Padmanaban, and M. M. Pastor-Blas

Copyright ( 2011 P. Poomalai et al. This is an open access article distributed under the Creative Commons Attribution License, which permits unrestricted use, distribution, and reproduction in any medium, provided the original work is properly cited.

\begin{abstract}
Binary blends of poly(methyl methacrylate) (PMMA)/copoly(ether-ester) (COPE) elastomer were prepared under four different compositions by melt mixing technique using twin-screw extruder. The effects of COPE content on thermal and dynamic mechanical properties were investigated using various techniques such as thermogravimetric analysis (TGA), differential scanning calorimetric analysis (DSC), and dynamic mechanical analysis (DMA) for all PMMA/COPE blends. The properties of all the blends were evaluated in comparison with neat PMMA and COPE. All the blends show higher thermal stability than individual component. DSC analysis results reveal that all the blends show two glass transition temperature $\left(T_{g}\right)$ values and the $T_{g}$ value of PMMA has been shifted to lower side due to the presence of COPE content. The two step reduction in storage modulus corresponding to their $T_{g}$ value reveal that the blends are immiscible in nature.
\end{abstract}

\section{Introduction}

In recent times, polymer blends have emerged as a frontier area of research activity in polymer technology. To create a new material with properties beyond those achievable with a single polymer by blending technique has become a challenging area for polymer technologists [1]. Most of the blends are incompatible, and their property depends on compositions and compatibility among the constituents. Many thermoplastics are being blended together mainly to improve the impact strength or toughness out of all other properties. Among amorphous thermoplastics, poly(methyl methacrylate) is one of the most important polymers due to its unique characteristics such as transparency, dimensional stability, and weathering resistance. But it suffers from brittleness and poor chemical resistance. Many scientists have been studied the toughness of this brittle polymer [24]. Gloaguen et al. [5] studied the effect of the rubber particle size on the plasticity of toughened PMMA blends. They considered PMMA blends containing latex particles with a soft core and a hard shell. Lovell et al. [6] prepared multiplelayer toughening particles as impact modifiers for PMMA. Franck and Lehmann [7] have made an important contribution to understanding of rubber toughening of PMMA blends at different deformation speed. Kilwon et al. [8] have investigated the effect of interfacial adhesion on toughening behaviour of rubber-modified PMMA. Toughened PMMA has been successfully prepared by incorporating rubber particles [9]. They achieved superior toughness values with the average particle size of $50 \mathrm{~nm}$ in 70:30 PMMA/Rubber blend. Blends of PMMA with poly(ethylene terephthalate) (PET) show good processability and high impact strength [10]. Fracture toughness and mechanical behaviour of thermoplastic copoly(ether-ester) (COPE) elastomer toughened acrylonitrile butadiene styrene (ABS) were reported by Sivaraman et al. [11].

The important aspect of all polymer mixtures is the phase behaviour in the solid as well as molten state. Behaviour in 


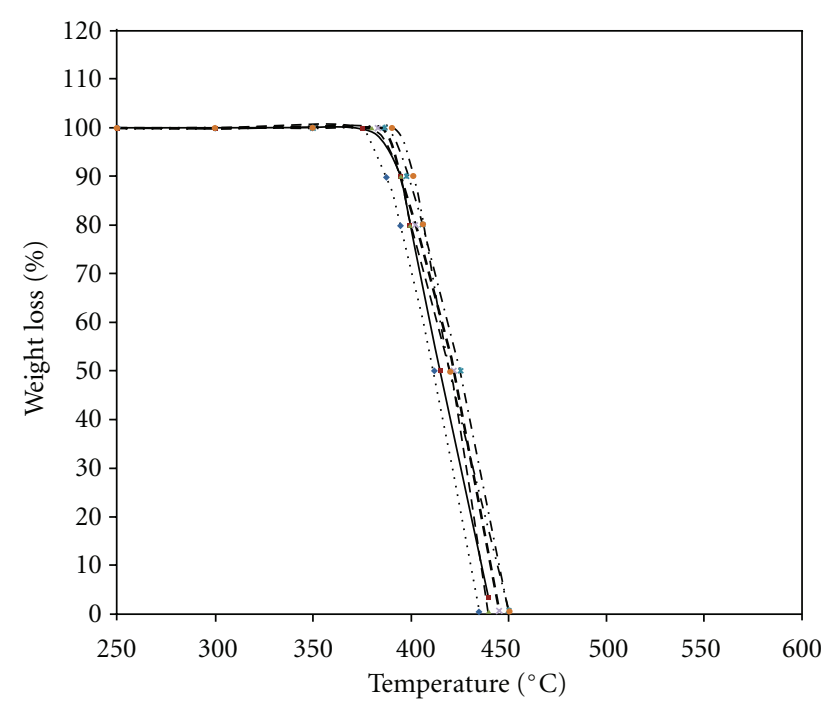

PMMA/COPE

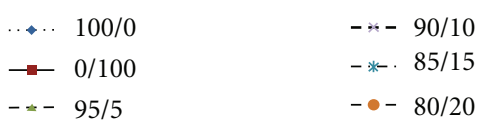

FIgURE 1: TGA thermograms for PMMA, COPE, and their blends.

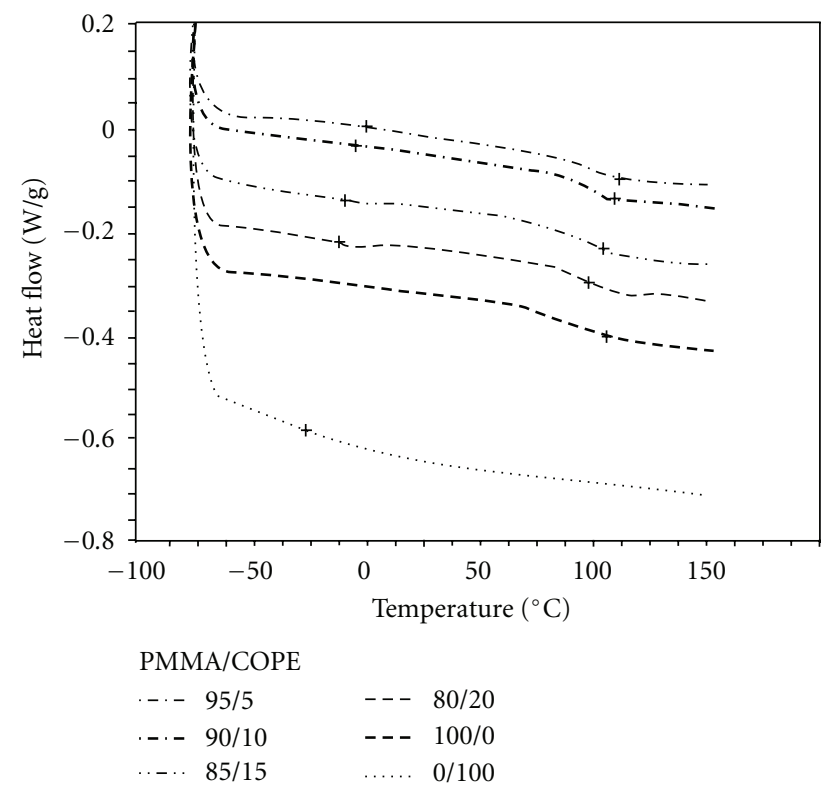

FIgURE 2: DSC thermograms for PMMA, COPE, and their blends.

the solid state is traditionally assessed by examining the number and location of $T_{g}$. Thermal analysis techniques such as DSC are generally employed for measurement of $T_{g}$. This DSC test procedure is normally done by polymer chemists to test the compatibility (miscibility) of blends/emulsions [12]. $T_{g}$ has become an important parameter in the field of polymer rheology which in turn can be used to describe the mechanical properties of the polymer materials [13]. The $T_{g}$ depends on the molecular mobility of materials in crystalline as well as amorphous structures. For synthetic polymers in the amorphous state, a relaxation region associated with the glass transition is observed at temperatures around and above $T_{g}$.

Recently, authors have reported the improvement in impact strength and other properties of PMMA by the addition of thermoplastic elastomers (TPEs) such as thermoplastic polyurethane, Ethylene Vinyl Acetate, and COPE [14-16]. Thermoplastic copoly(ether-ester) has most of the desirable characteristics of high-performance elastomer and flexible plastics. Its features are exceptional toughness and resilience, high resistance to creep, impact and flex fatigue, flexibility at low temperature, high elasticity, and retention of properties at elevated temperature. In addition, it resists deterioration from many industrial chemicals, oils, and solvents. This paper presents the thermal and dynamic mechanical behaviours of PMMA/COPE blends. The main objective of this investigation is to study the thermal characteristics of PMMA/COPE blends and the effect of COPE content on the thermal stability and dynamic mechanical characteristics of the PMMA/COPE blends.

\section{Experimental}

2.1. Materials. Poly(methyl methacrylate) (Gujpol-P 876G) with density $1.19 \mathrm{~g} / \mathrm{cc}$ and melt flow index $1.35 \mathrm{~g} / 10 \mathrm{~min}$, was obtained from M/s Gujarat State Fertilizers Company Limited, India. The copoly(ether-ester) (Hytrel 4069) with density $1.11 \mathrm{~g} / \mathrm{cc}$ obtained from M/s DuPont, USA was used.

2.2. Blend Preparation. The blends of PMMA and COPE under different compositions, namely, 100/0, 95/5, 90/10, $85 / 15$, and $80 / 20 \mathrm{wt} \%$, were prepared by melt mixing technique using corotating twin-screw extruder (L/D ratio 18:1) of Haake Rheocord 9000 (Germany). The polymers were pre-dried in hot air oven at $80^{\circ} \mathrm{C}$ for $4 \mathrm{hrs}$ before mixing. The pre-dried granules of PMMA and COPE were mixed as per the compositions, mechanically and fed in to the extruder. The processing temperature range of 145$210^{\circ} \mathrm{C}$ and screw speed of $30 \mathrm{rpm}$ were used. The extruded strands passing through the water bath were cut into pellets and vacuum dried and were used for thermo-mechanical studies.

2.3. Characterization Techniques. The thermal stability studies of PMMA, COPE, and their blends were carried out using thermogravimetric analyser (Pyris 201, Perkin Elmer, USA), from ambient temperature to $600^{\circ} \mathrm{C}$ at a heating rate of $10^{\circ} \mathrm{C} / \mathrm{min}$ at $\mathrm{N}_{2}$ atmosphere. The weight loss with respect to temperature was recorded. The thermal analysis of PMMA, COPE, and their blends were also carried out by using DSC (Q20), TA Instruments Inc., USA. The dynamic DSC run was recorded at a heating rate of $10^{\circ} \mathrm{C} / \mathrm{min}$ under $\mathrm{N}_{2}$ atmosphere. For each analysis about $6 \mathrm{mg}$ of sample is used, and scans were recorded in the temperature range -85 to $140^{\circ} \mathrm{C}$. The DSC instrument was calibrated using pure indium metal. The DMAs of all the blends and the virgin PMMA and COPE were also carried out by dynamic mechanical analyzer, 
TABLE 1: TGA thermal characteristics of PMMA, COPE and their blends.

\begin{tabular}{|c|c|c|c|c|c|c|}
\hline \multirow{2}{*}{$\begin{array}{l}\text { Composition of PMMA/COPE } \\
\text { blends (wt./wt.\%) }\end{array}$} & \multicolumn{5}{|c|}{ Temperature at different $\%$ mass loss $\left( \pm 2^{\circ} \mathrm{C}\right)$} & \multirow{2}{*}{ Ash content $(\%)$} \\
\hline & $T_{0}$ & $T_{10}$ & $T_{20}$ & $T_{50}$ & $T_{\max }$ & \\
\hline $100 / 0$ & 375 & 388 & 398 & 408 & 432 & 0.5 \\
\hline $95 / 05$ & 385 & 395 & 400 & 420 & 440 & 0.5 \\
\hline $90 / 10$ & 390 & 395 & 402 & 422 & 445 & 0.6 \\
\hline $85 / 15$ & 395 & 398 & 405 & 425 & 450 & 0.7 \\
\hline $80 / 20$ & 400 & 400 & 405 & 420 & 450 & 0.9 \\
\hline $0 / 100$ & 380 & 395 & 400 & 410 & 440 & 3.5 \\
\hline
\end{tabular}

$T_{0}$ : Temperature of onset of decomposition; $T_{10}$ : Temperature for $10 \%$ mass loss; $T_{20}$ : Temperature for $20 \%$ mass loss; $T_{50}$ : Temperature for $50 \%$ mass loss; $T_{\max }$ : Temperature for maximum mass loss.

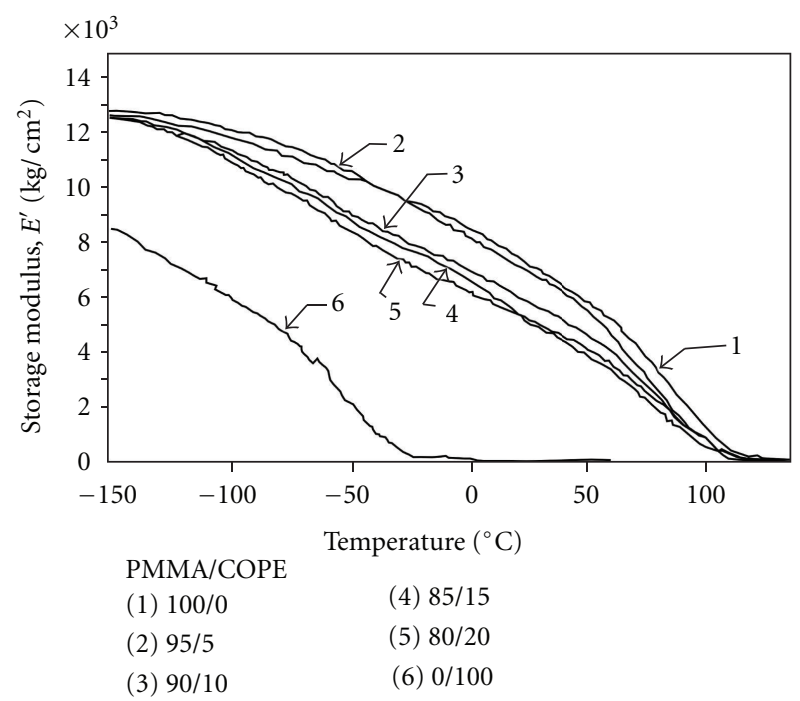

FIgURE 3: Effect of COPE addition on storage modulus of PMMA/COPE blends.

model 242 made by NETZSCH Geratebau GmbH, Germany. Rectangular-shape moulded sample was used for testing in the single cantilever mode to measure the storage modulus $\left(E^{\prime}\right)$, the loss modulus $\left(E^{\prime \prime}\right)$, and the phase angle as expressed by $\operatorname{Tan} \delta$. Sample was cooled from room temperature to $-150^{\circ} \mathrm{C}$, kept isothermally at this temperature for $5 \mathrm{~min}$ to equilibrate, and subsequently DMA thermogram was recorded in the temperature range -150 to $150^{\circ} \mathrm{C}$ at a heating rate of $2^{\circ} \mathrm{C} / \mathrm{min}$ under $\mathrm{N}_{2}$ gas purge.

\section{Results and Discussion}

3.1. Thermogravimetric Analysis. Thermogravimetric analysis in terms of weight loss curves of PMMA, COPE, and their blends are shown in Figure 1. The thermograms of PMMA, COPE and their blends show single-stage degradation. The ash content obtained after complete decomposition reached a minimum $0.5 \%$ in the case of virgin PMMA and marginally increases as COPE content increases in its blends and maximum ash in the case of pure COPE (3.5\%).
TABLE 2: Thermo gravimetric analysis data obtained from derivative TGA curves of PMMA, COPE and their blends.

\begin{tabular}{lccc}
\hline $\begin{array}{l}\text { Composition of PMMA/COPE } \\
\text { blends (wt./wt.\%) }\end{array}$ & \multicolumn{3}{c}{ Transition temperature range } \\
& $T_{i}$ & $T_{p}$ & $T_{c}$ \\
\hline $100 / 0$ & 375 & 412 & 438 \\
$95 / 05$ & 380 & 420 & 440 \\
$90 / 10$ & 395 & 422 & 445 \\
$85 / 15$ & 388 & 425 & 450 \\
$80 / 20$ & 392 & 420 & 450 \\
$0 / 100$ & 375 & 412 & 442 \\
\hline
\end{tabular}

$T_{i}$ : temperature at which decomposition starts; $T_{p}$ : temperature at which decomposition rate maximum; $T_{c}$ : Temperature at which decomposition completed.

TABle 3: $T_{g}$ obtained from DSC of PMMA, COPE, and their blends.

\begin{tabular}{lcc}
\hline Composition of PMMA/COPE & \multicolumn{2}{c}{$T_{g}\left( \pm 1^{\circ} \mathrm{C}\right)$} \\
blends (wt./wt.\%) & $T_{g 1}$ & $T_{g 2}$ \\
\hline $100 / 0$ & - & 100.6 \\
$95 / 05$ & -5.0 & 98.9 \\
$90 / 10$ & -9.0 & 97.0 \\
$85 / 15$ & -13.2 & 95.0 \\
$80 / 20$ & -15.0 & 90.0 \\
$0 / 100$ & -38.1 & - \\
\hline
\end{tabular}

TABLE 4: $T_{g}$ obtained from DMA thermograms of PMMA, COPE, and their blends.

\begin{tabular}{lcc}
\hline Composition of PMMA/COPE & \multicolumn{2}{c}{$T_{g}$ values $\left( \pm 1^{\circ} \mathrm{C}\right)$} \\
blends (wt./wt.\%) & $T_{g 1}$ & $T_{g 2}$ \\
\hline $100 / 0$ & - & 100.2 \\
$95 / 05$ & -12.0 & 98.6 \\
$90 / 10$ & -16.1 & 98.2 \\
$85 / 15$ & -24.4 & 96.9 \\
$80 / 20$ & -28.0 & 96.8 \\
$0 / 100$ & -48.1 & - \\
\hline
\end{tabular}




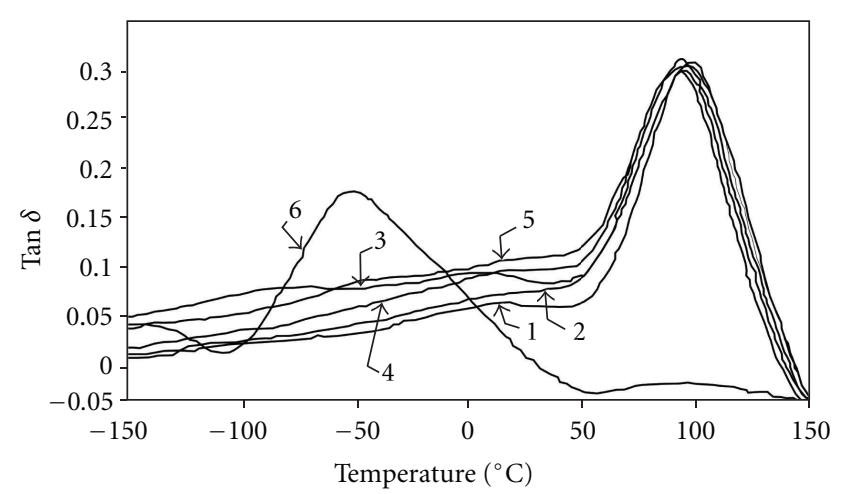

PMMA/COPE
(1) $100 / 0$
(4) $85 / 15$
(2) $95 / 5$
(5) $80 / 20$
(3) $90 / 10$
(6) $0 / 100$

Figure 4: Effect of COPE addition into PMMA on Tan $\delta$ of PMMA/COPE blends.

The characteristic temperatures obtained from the TGA curves of the virgin materials and their blends are summarized in Tables 1 and 2. The initial decomposition temperature is low for the PMMA $\left(375^{\circ} \mathrm{C}\right)$ and high for PMMA/COPE $(80 / 20)\left(400^{\circ} \mathrm{C}\right)$ blend. The thermal stability of PMMA and its blends is more or less same. The temperature at which the maximum weight loss occurs is designated as $T_{\max }$ for PMMA is $432^{\circ} \mathrm{C}$ and for COPE it is at $440^{\circ} \mathrm{C}$. The $T_{\max }$ increases with increase in COPE content in the blends. The temperature at which the decomposition completed $\left(T_{c}\right)$ shows its minimum for PMMA $\left(438^{\circ} \mathrm{C}\right)$ and for COPE $\left(442^{\circ} \mathrm{C}\right)$ and $T_{\max }$ increases with increase in COPE content in the blends. This indicates that PMMA/COPE require higher temperature for complete decomposition. This is once again reflected in $T_{50}$, that is, temperature at which $50 \%$ wt. loss. The possible explanation of the higher thermal stability of the blends in comparison with the virgin PMMA is that, during thermal degradation, the polymer degrades rapidly and leads to cross-linking reactions and formation of a protective layer, which may be more stable in comparison with the virgin material. From Table 1, it is noticed the lower values of ash content (0.5\%) for PMMA and (3.5\%) for COPE. Based upon the mass of carbonaceous char, it is concluded that COPE improves the flame retardancy [17].

3.2. Differential Scanning Calorimetry. The DSC thermograms of virgin PMMA, COPE, and their blends are shown in Figure 2. The glass transition temperature, that is, onset of change in the heat capacity which was used to describe the motion of the polymer chain segment. The obtained $T_{g}$ values of the blends from DSC thermograms are given in Table 3. The virgin PMMA and COPE show single $T_{g}$ at $100.6^{\circ} \mathrm{C}$ and $-38.1{ }^{\circ} \mathrm{C}$, respectively, whereas their blends show two $T_{g}$ 's which indicates the heterogeneous nature and immiscibility. In PMMA/COPE blends, as COPE content increases the $T_{g}$ corresponding to PMMA shows shift towards lower temperature side which may be due to plasticization effect of COPE in the blends. The $T_{g}$ corresponding to PMMA component decreases from $100.6^{\circ} \mathrm{C}$ to $90^{\circ} \mathrm{C}$, similarly $T_{g}$ corresponding to COPE shifts from $-38.1^{\circ} \mathrm{C}$ to $-5^{\circ} \mathrm{C}$. The increase in soft component in PMMA, which generally increases the segmental motion of the polymer networks of the blend which imparts lowering of $T_{g}$ value of PMMA.

3.3. Dynamic Mechanical Analysis. The dynamic mechanical analysis involves the study of dynamic mechanical response of viscoelastic materials to sinusoidally varying strain and is useful in material development [18]. The dynamic modulus indicates the inherent stiffness of the material under dynamic loading conditions. A few polymeric mixtures are compatible and form single homogeneous phase. However, most polymer blends form two phases due to incompatibility of the components. The storage modulus and temperature curves of virgin PMMA, COPE, and their blends containing 5, 10, 15 , and $20 \%$ of the COPE are shown in Figure 3 . The $T_{g}$ obtained from DMA thermograms is given in Table 4. The break in modulus curves remains steep, and the modulus is just shifted on temperature scale in proportion to the relative composition of the polymer blends. But, the break in modulus of the curves near $T_{g}$ is not so steep. The two steps in the dynamic modulus-temperature curves, which are very much visible with increase in COPE content, are the characteristics of an immiscible two-phase blend system [19]. The DMA analysis has been carried out to study the effect of COPE content on the storage modulus of PMMA/COPE blends. For all the blend compositions, the storage modulus can be seen decreasing in the investigated temperature range, indicating that the introduction of COPE reduces the storage modulus. The variation of storage modulus is depends on the COPE content. The blends undergo two step reductions in storage modulus, one at the $T_{g}$ of COPE and the other one at the $T_{g}$ of PMMA.

With an increase in COPE content, the reduction of storage modulus at the $T_{g}$ of COPE region is more and vice versa. The modulus of elasticity in the glassy state for the two blends is shown to decrease with increasing COPE content. This result is expected because the material incorporated was a low modulus and flexible material.

The variation of $\operatorname{Tan} \delta$ as a function of temperature for all blends is shown in Figure 4. For these blends, the damping temperature curve shows two peaks; each peak is the characteristic of $T_{g}$ of the individual components. The COPE has maximum dampness at $-48.1^{\circ} \mathrm{C}$, whereas its blends with PMMA have dampness at $-28.0,-24.0,-16.1$, and -12.0 for $20,15,10$ and $5 \%$ of COPE, respectively, $\left(T_{g 1}\right)$ (Table 4). Similarly, $T_{g}$ for PMMA 100.2 has been decreased to 98.6, 98.2, 96.9, and 96.8, respectively, for COPE content $5,10,15$, and $20 \%$. The magnitude of the peak is more or less characteristic of the relative concentration of the components, whether or not the phases are dispersed or continuous $[20,21]$. For instance, at a given concentration, $\operatorname{Tan} \delta$ is greater in the high-temperature damping peak, if 
the polymer with high $T_{g}$ value is in continuous phase [20]. It is clear from Table 4 that the $T_{g}$ has broadened with increase in COPE content, indicating reduction in miscibility with increase in COPE content.

\section{Conclusion}

Blends of PMMA with thermoplastic copoly(ether-ester) elastomer (COPE) under different compositions (5 to $20 \mathrm{wt} \%$ COPE) were prepared by using twin-screw extruder. The thermal behaviour of PMMA/COPE blends show that the presence of COPE increases the thermal stability of PMMA. DSC and DMA analysis results show that two $T_{g}$ 's for all the blends indicating incompatible two phase system and compatibility reduces with increase in COPE content. The blends undergo two step reductions in storage modulus, one at $T_{g}$ of COPE and the other at $T_{g}$ of PMMA. The damping characteristics also show two peaks each for COPE and PMMA in which higher broadening of damping peaks for the blends with higher COPE content indicates incompatibility.

\section{References}

[1] L. H. Sperling, Polymeric Multi-Components Materials, John Wiley \& Sons, New York, NY, USA, 1997.

[2] M. Schneider, T. Pith, and M. Lambla, "Impact modification of thermoplastics by methyl methacrylate and styrene-grafted natural rubber latexes," Polymers for Advanced Technologies, vol. 6, no. 5, pp. 326-334, 1995.

[3] S. Jun-Yeob, K. Jin-Woong, and S. Kyung-Do, "Poly(methyl methacrylate) toughening with refractive index-controlled core-shell composite particles," Journal of Applied Polymer Science, vol. 71, no. 10, pp. 1607-1614, 1999.

[4] M. Schneider, T. Pith, and M. Lambla, "Impact modification of thermoplastics by methyl methacrylate and styrene-grafted natural rubber latexes," Polymers for Advanced Technologies, vol. 6, no. 5, pp. 326-334, 1995.

[5] J. M. Gloaguen, P. Heim, P. Gaillard, and J. M. Lefebvre, "Plasticity of rubber-toughened poly(methyl methacrylate): effect of rubber particle size," Polymer, vol. 33, no. 22, pp. 4741-4746, 1992.

[6] P. A. Lovell, J. McDonald, D. Saunders, and E. R. Young, "Studies of rubber-toughened poly(methyl methacrylate): 1 . Preparation and thermal properties of blends of poly(methyl methacrylate) with multiple-layer toughening particles," Polymer, vol. 34, no. 1, pp. 61-69, 1993.

[7] O. Frank and J. Lehmann, "Determination of various deformation processes in impact-modified PMMA at strain rates up to $105 \%$ min," Colloid \& Polymer Science, vol. 264, no. 6, pp. 473-481, 1986.

[8] C. Kilwon, Y. JaeHo, and C. E. Park, "The effect of interfacial adhesion on toughening behaviour of rubber modified poly(methyl methacrylate)," Polymer, vol. 38, no. 20, pp. 51615167, 1997.

[9] B. J. P. Jansen, S. Rastogi, H. E. H. Meijer, and P. Lemstra, "Rubber-modified glassy amorphous polymers prepared via chemically induced phase separation. 1. Morphology development and mechanical properties," Macromolecules, vol. 34, no. 12, pp. 3998-4006, 2001.
[10] L. A. Utracki, Polymer Blends Handbook, vol. 1, Kluwer Academic Publishers, Dodrecht, The Netherlands, 2002.

[11] P. Sivaraman, L. Chandrasekhar, V. S. Mishra, B. C. Chakraborty, and T. O. Varghese, "Fracture toughness of thermoplastic co-poly (ether ester) elastomer-Acrylonitrile butadiene styrene terpolymer blends," Polymer Testing, vol. 25, no. 4, pp. 562-567, 2006.

[12] J. H. Jagannath, C. Nanjappa, D. D. Gupta, and A. S. Bawa, "Studies on the stability of an edible film and its use for the preservation of carrot (Daucus carota)," International Journal of Food Science and Technology, vol. 41, no. 5, pp. 498-506, 2006.

[13] Y. Roos, "Characterization of food polymers using state diagrams," Journal of Food Engineering, vol. 24, no. 3, pp. 339360, 1995.

[14] P. Poomalai and Siddaramaiah, "Studies on poly(methyl methacrylate) (PMMA) and thermoplastic polyurethane (TPU) blends," Journal of Macromolecular Science A: Pure and Applied Chemistry, vol. 42, no. 10, pp. 1399-1407, 2005.

[15] P. Poomalai, B. Ramaraj, and Siddaramaiah, "Poly(methyl methacrylate) toughened by ethylene-vinyl acetate copolymer: physico-mechanical, thermal, and chemical properties," Journal of Applied Polymer Science, vol. 104, no. 5, pp. 3145-3150, 2007.

[16] P. Poomalai, T. O. Varghese, and Siddaramaiah, "Investigation on thermoplastic co-poly(ether-ester) elastomer toughened poly(methylmethacrylate) blends," Journal of Applied Polymer Science, vol. 109, no. 6, pp. 3511-3518, 2008.

[17] D. Parida, S. Lenka, P. L. Nayak et al., "Polymers from renewable resources. IV. castor-oil-based interpenetrating polymer networks derived from isophorone diisocyanate poly(acrylamide) and poly(methacrylamide)," Journal of Macromolecular Science: Pure and Applied Chemistry, vol. 32, no. 7, pp. 1365-1379, 1995.

[18] A. B. Mathur and I. S. Bharadwaj, Testing and Evaluation of Plastics, Allied, New Delhi, India, 2003.

[19] I. M. Ward, Mechanical Properties of Solid Polymers, John Wiley \& Sons, New York, NY, USA, 1971.

[20] T. Miyamoto, K. Kodama, and K. Shibayama, "Structure and properties of a styrene-butadiene-styrene block copolymer," Part A-2: Polymer Physics, vol. 8, no. 12, pp. 2095-2103, 1970.

[21] R. Buchdahl and L. E. Nielsen, "Transitions in high polymeric materials," Journal of Applied Physics, vol. 21, no. 6, pp. 482487, 1950. 

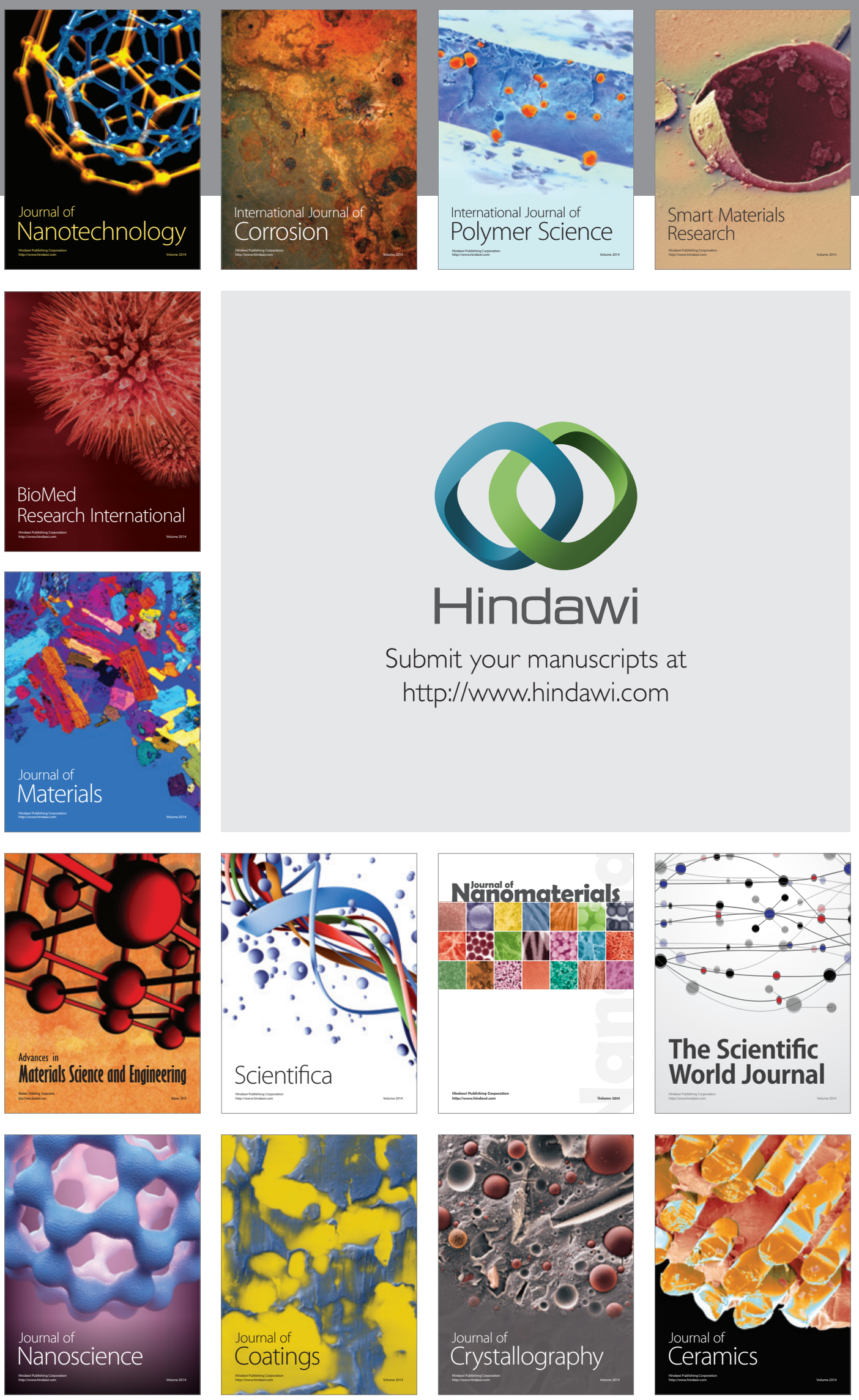

The Scientific World Journal

Submit your manuscripts at

http://www.hindawi.com

\section{World Journal}

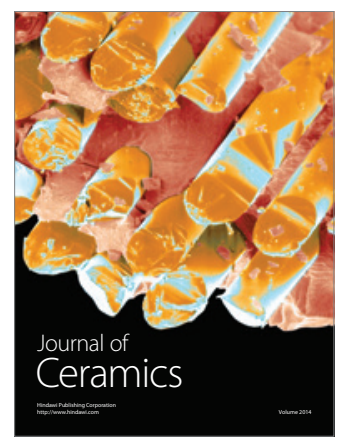

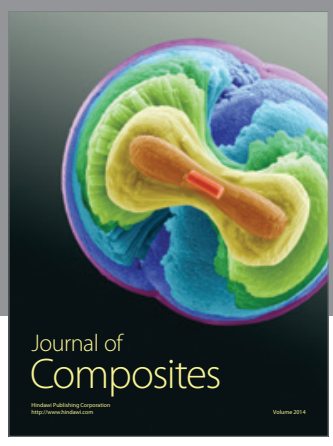
